\title{
MÉTODOS DE SOMA TÉRMICA NA DETERMINAÇÃO DE PLASTOCRONO DE Helianthus annuus L. CULTIVADO EM AMBIENTE PROTEGIDO EM CAPITÃO POÇO-PA
}

\author{
SOUZA, Leane Castro de ${ }^{1}$ \\ COSTA, Antonia Vanderlane Albuquerque $\mathrm{da}^{2}$ \\ MOREIRA, Wendel Kaian Oliveira ${ }^{2}$ \\ SILVA, Euzanyr Gomes da ${ }^{2}$ \\ SOUZA, Anajeysa Carvalho de ${ }^{2}$ \\ SILVA, Raimundo Thiago Lima da
}

RESUMO: A temperatura do ar é um dos principais parâmetros agrometeorológico que afeta a fenologia das culturas agrícolas, por está principalmente relacionada a taxa de fotossíntese, afetando também o plastocrono. Com isso, esse fato tem motivado a realização de inúmeros trabalhos sobre este fenômeno, utilizando-se diversos métodos para a mensuração e estimativa desta influência. Objetivou-se com este trabalho avaliar os métodos de determinação de graus-dia para estimação do plastocrono em duas cultivares de girassol, em capitão Poço-PA. Assim, se conduziu um experimento em casa de vegetação na área experimental da Universidade Federal Rural da Amazônia. Desse modo, utilizaram-se duas cultivares (cv.) de girassol (Embrapa-122 e Catissol) e utilizou-se 120 vasos experimentais. Para calcular a soma térmica diária foram utilizados seis métodos. Dessa forma, o melhor método para estimativa do plastocrono foi o Método 3, que leva em consideração a temperatura média, a temperatura base inferir e a temperatura ótima, pois foi o que apresentou menor desvio padrão em relação aos demais métodos.

Palavras-chave: Graus dias. Embrapa-122. Catissol. Temperatura do ar

SUMMARY: The air temperature is one of the main agro-meteorological parameters that affect the phenology of crops for is mainly related to photosynthesis rate also affecting plastochron. Thus, this fact has motivated the realization of numerous works on this phenomenon, using various methods to measure and estimate this influence. The objective of this study was to evaluate methods for the determination of degree days to estimate the plastochron in two sunflower cultivars in Capitão Poço. Thus, an experiment was conducted in a greenhouse in the experimental area of the Amazon Rural Federal University. Thus, they use two cultivars (cv.) Sunflower (EMBRAPA-122 and Catissol) 120 and used experimental vessels. To calculate the thermal time two methods were used. Thus, the best method to estimate plastochron was Method 3, which takes into account the average temperature, the base temperature and inferring the optimum temperature, it showed the lowest standard deviation relative to other methods.

Keywords: Degree days . Embrapa -122 . Catissol. Air temperature.

\section{INTRODUÇÃO}

O girassol (Helianthus annuus L.) apresenta ampla utilização na alimentação animal sob as formas de silagem, forragem fresca picada, torta e os aquênios são também matéria prima utilizada na extração de óleo para a produção do biodiesel como energia alternativa (SILVA et al. 2016). De acordo com a

\footnotetext{
${ }^{1}$ Engenheira Agrônoma pela Universidade Federal Rural da Amazônia - UFRA, Mestranda em Agronomia (Ciência do Solo) Pela Universidade Estadual Paulista- UNESP, Faculdade de Ciências Agrárias e Veterinárias - Campus de Jaboticabal, com ênfase na área de Mecanização Agrícola.

${ }^{2}$ Estudante de Agronomia da Universidade Federal Rural da Amazônia - UFRA

${ }^{3}$ Professor Dr. da Universidade Federal Rural da Amazônia, Campus de Capitão Poço-PA
} 
CONAB (2010), foram cultivados no Brasil em torno de 71000 ha na safra 2009/2010 com uma produtividade média de $1137 \mathrm{Kg} \mathrm{ha}^{-1}$.

Segundo Pereira et al. (2010), a temperatura do ar é um dos principais parâmetros agrometeorológico que afeta a fenologia das culturas agrícolas, por estar principalmente relacionada a taxa de fotossíntese, afetando também o plastocrono. Esse fato tem levado vários pesquisadores a estudar diversos métodos a respeito desse fenômeno com intuito de se mensurar e estimar a sua influência. Segundo Ferneda et al. (2016) contextualiza que a interferência climática pode afetar várias fases fenológicas de germinação, florescimento e enchimento de grãos, com isso relata que a época de semeadura mais indicada para soja dependera, principalmente, da temperatura do solo e da umidade do solo para a germinação, da temperatura do ar, do regime de chuvas durante todo o ciclo da planta, do fotoperíodo após a emergência e da umidade do solo na floração e no enchimento de grãos.

Uma das formas de se mostrar o efeito da temperatura sobre o desenvolvimento vegetal é através da soma térmica (GILMORE JUNIOR; ROGERS, 1958). Na equação dos graus-dia subtrai-se a temperatura média do ar da temperatura base da espécie em estudo (ARNOLD, 1959). Com isso, existe uma gama de trabalhos utilizando métodos de cálculo que consideram uma ótica de resposta linear dos fenômenos de crescimento das culturas agrícolas, à temperatura do ar (WILHELM; McMASTER, 1995).

Assim, conseguir quantificar o desenvolvimento vegetal é de grande importância nos estudos da biologia de espécies, uma vez que este está relacionada com parâmetros como a diferenciação celular, a iniciação e o aparecimento de órgãos na planta, estendendo-se até a senescência, sendo de fundamental importância para fins de manejo das espécies vegetais (WILHELM; McMASTER, 1995). A interceptação da radiação solar não depende apenas do IAF, mas também de um conjunto de fatores, como tamanho e ângulo da folha, número de folhas, condições meteorológicas e práticas de manejo (SCHWERZ et al. 2016).

Um exemplo de parâmetro de desenvolvimento vegetal é o número de nós acumulados (NN) na haste principal (FAGUNDES et al. 2008). Sendo que, o cálculo do NN na haste principal, nos modelos matemáticos, é realizado por meio do conceito de plastocrono, que é definido como o intervalo de tempo entre o aparecimento de dois nós sucessivos em uma planta ( STRECK et al. 2005), e a unidade de tempo utilizada no cálculo de plastocrono é a soma térmica, com unidade em ${ }^{\circ} \mathrm{C}$ dia nó ${ }^{-1}$. Utilizado para a quantificação do efeito da temperatura do ar sobre o desenvolvimento das plantas (GILMORE; ROGERS, 1958).

Para se fazer a estimativa da soma térmica diária, pode-se agrupar os métodos de cálculo em duas categorias, onde uma está relacionada ao uso das temperaturas cardinais do desenvolvimento da planta, e outra ao emprego das temperaturas do ar.

Também se pode considerar um valor máximo de acúmulo térmico diário na Tot; para temperaturas supra ótimas, em que o acúmulo térmico não é maior do que o acúmulo na Tot pode-se até mesmo considerar um decréscimo linear até zero do acúmulo térmico na TB (STRECK et al. 2007b).

Desse modo, o conceito da soma térmica ou dos graus dia é muito utilizado para a quantificação do efeito da temperatura do ar sobre o desenvolvimento das plantas (GILMORE; ROGERS, 1958), sendo uma das melhores medidas de tempo biológico que dias do calendário civil ou dias após a semeadura (GILMORE; ROGERS, 1958). Trabalhos com soma térmica já foram aplicados a cultura da morangueira (MENDONÇA et al, 2012; TAZZO et al. 2015), oliveira (MARTINS et al. 2012), feijão-caupi (FARIAS et al. 2015), melancia (LUCAS et al., 2011).

Nesse contexto, o objetivo deste trabalho foi avaliar os métodos de determinação de graus- dia para estimação do plastocrono em duas cultivares de girassol, no município de capitão Poço estado do Pará. 


\section{MATERIAL E MÉTODO}

O experimento foi conduzido na casa de vegetação da Universidade Federal Rural da Amazônia

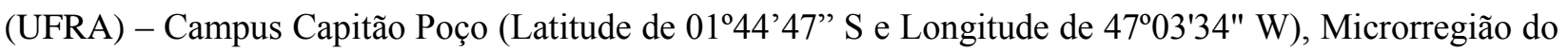
Guamá, localizada a $226 \mathrm{~km}$ da capital Belém.

O município apresenta uma amplitude de 25,7 a $26,9^{\circ} \mathrm{C}$ com média anual de $26,2^{\circ} \mathrm{C}$, apenas $1,2^{\circ} \mathrm{C}$ de variação, e conforme a classificação Köeppen o clima tipo Ami (SILVA et al. 2011), com precipitação anual em torno de $2.500 \mathrm{~mm}$ e com uma curta estação seca entre Setembro e Novembro (precipitação mensal em torno de $60 \mathrm{~mm}$ ), além de uma umidade relativa do ar entre $75 \%$ e $89 \%$, nos meses com menor e maior precipitação, respectivamente (SCHWART, 2007).

Desse modo, utilizaram-se duas cultivares (cv.) de girassol (Embrapa-122 e Catissol), onde a semeadura foi realizada nos dias 24 de Novembro e 11 de Dezembro, para ambas as cv, no ano agrícola de 2014.

O solo utilizado é classificação como Latossolo Amarelo Álico (EMBRAPA, 2006), com condições químicas e físicas apresentada de, $\mathrm{pH}$ Água $=4,5$; Condutividade elétrica $=0,25 \mathrm{dS} \mathrm{m} ; \mathrm{Ca}^{2+}=$ $0,70 \mathrm{cmol}_{\mathrm{c}} \mathrm{Kg} ; \mathrm{Mg}^{2+}=0,60 \mathrm{cmol}_{\mathrm{c}} \mathrm{Kg} ; \mathrm{Na}^{+}=0,05 \mathrm{cmol}_{\mathrm{c}} \mathrm{Kg} ; \mathrm{K}^{+}=0,09 \mathrm{cmol}_{\mathrm{c}} \mathrm{Kg}, \mathrm{H}^{+}+\mathrm{Al}^{3+}=4,46 \mathrm{cmol}_{\mathrm{c}} \mathrm{Kg}$; $\mathrm{Al}^{3+}=0,80 \mathrm{cmol}_{\mathrm{c}} \mathrm{Kg} ; \mathrm{S}=1,4 \mathrm{cmol}_{\mathrm{c}} \mathrm{Kg} ; \mathrm{T}=5,9 \mathrm{cmol}_{\mathrm{c}} \mathrm{Kg} ; \mathrm{C}=8,52 \mathrm{~g} \mathrm{Kg} ; \mathrm{N}=0,86 \mathrm{~g} \mathrm{Kg} ; \mathrm{C} / \mathrm{N}=10 ;$ M.O. $=$ $14,69 \mathrm{~g} \mathrm{Kg} ; \mathrm{V}=24 \% ; \mathrm{m}=36 \%$; P Assimilável $=8 \mathrm{~m} \mathrm{~kg}^{-1}$; Ucc $(0,1$ bar $)=17,82 \%$; Upmp (15 bar $)=$ $7,13 \%$; DS $=1,93 \mathrm{~g} \mathrm{~cm}^{3} ; \mathrm{DP}=2,85 \mathrm{~g} \mathrm{~cm}^{3}$.

O solo teve a necessidade 1,04 $\mathrm{t} \mathrm{ha}^{-1}$, a adubação de fundação para as duas cultivares consistiu de $60 \mathrm{~kg} \mathrm{ha}^{-1}$ de N; $100 \mathrm{~kg} \mathrm{ha}^{-1}$ de $\mathrm{P}^{2} \mathrm{O}^{5}$, sendo este aplicado o SFS (Superfosfato simples) em dose única no plantio; e $80 \mathrm{~kg} \mathrm{ha}^{-1}$ de $\mathrm{K}^{2} \mathrm{O}$. A adubação com $\mathrm{KCl}$ e ureia, foi distribuída em duas aplicações, a primeira no plantio e a segunda 15 dias após a primeira aplicação.

Foram utilizados 120 vasos experimentais de polietileno preto com 5L de capacidade, espaçados entre $0,5 \mathrm{~m}$ ou $50 \mathrm{~cm}$ cada, onde foram preenchidos com o solo local.

Foram semeadas duas sementes por vaso. A partir da germinação foi realizado o desbaste, sendo retiradas as plantas inferiores e com alguma deformação, ficando apenas uma em cada unidade experimental (vaso).

Além disso, também foi realizado analises química e física do solo, a fim de observar a sua fertilidade e assim corrigir a deficiência de nutriente por meio da adubação e para determinar a lamina de água adequada para suprir as necessidades da cultura do girassol, além de verificar o comportamento físico do solo.

A amostra do solo utilizado no experimento foi analisada no Laboratório de Engenharia de Irrigação da Universidade Federal Rural da Amazônia campus Capitão Poço - PA.

Assim, as análises físicas do solo determinaram a lâmina de água de $372 \mathrm{ml}$ para os estádios iniciais, sendo aplicada no período matutino, no entanto, no decorrer do desenvolvimento das plantas, a exigência hídrica foi maximizada.

Mediante a esse fator fisiológico, a lâmina de água passou para $800 \mathrm{ml}$, sendo esta fracionada e aplicada no período matutino e vespertino, aplicando-se assim, $400 \mathrm{ml} \mathrm{em} \mathrm{ambos} \mathrm{os} \mathrm{períodos.}$

Durante o período experimental, os dados diários de temperatura mínima, máxima e instantânea do ar, bem como a umidade relativa do ambiente, foram monitorados e coletados diariamente às $7 \mathrm{~h}$, às $12 \mathrm{~h}$ e às $19 \mathrm{~h}$, durante todo o período do experimento, com o auxílio de um Termo-higrômetro da marca J.Prolab®, instalado a 1,5m de altura no centro da estufa.

Para calcular a soma térmica diária $\left(\mathrm{STd},{ }^{\circ} \mathrm{C}\right.$ dia) foram utilizados seis métodos (GILMORE JUNIOR ; ROGERS, 1958; STRECK et al. 2007a,b): 
1. $\quad$ Método 1: $\mathrm{STd}=($ Tméd $-\mathrm{Tb}) .1$ dia, se Tméd<Tb, então Tméd = Tb. (2);

2. $\quad$ Método 2: $\mathrm{STd}=(\mathrm{Tméd}-\mathrm{Tb}) .1$ dia, se Tmín $\leq \mathrm{Tb}$, então Tmín $=\mathrm{Tb}$. (3);

3. $\quad$ Método 3: $\mathrm{STd}=($ Tméd $-\mathrm{Tb}) .1$ dia, se Tméd<Tb, então Tméd $=\mathrm{Tb}$; se Tméd $>$ Tot, então Tméd = Tot. (4);

4. $\quad$ Método 4: $\mathrm{STd}=($ Tméd $-\mathrm{Tb}) .1$ dia, se Tmín $<\mathrm{Tb}$, então Tmín $=$ Tb e, se Tmáx $>$ Tot, então Tmáx $=$ Tot. (5);

5. Método 5: $\mathrm{STd}=($ Tméd $-\mathrm{Tb}) .1$ dia, quando $\mathrm{Tb}<\mathrm{Tméd} \leq \mathrm{Tot}$ e $\mathrm{STd}=\{(\mathrm{Tot}-\mathrm{Tb})$. $[(\mathrm{TB}-\mathrm{Tméd}) /(\mathrm{TB}-\mathrm{Tot})]\} .1$ dia, quando Tot $<$ Tméd $\leq \mathrm{TB}$; se Tméd $<\mathrm{Tb}$, então Tméd $=\mathrm{Tb}$; se Tméd $>$ TB, então Tméd $=$ TB (6);

6. Método 6: $\mathrm{STd}=($ Tméd $-\mathrm{Tb}) .1$ dia, quando $\mathrm{Tb}<\mathrm{Tméd} \leq \mathrm{Tot}$ e $\mathrm{STd}=\{(\mathrm{Tot}-\mathrm{Tb})$. [(TB-Tméd)/(TB - Tot)]\} .1 dia, quando Tot $<$ Tméd $\leq \mathrm{TB}$; se Tmín $<\mathrm{Tb}$, então Tmín $=\mathrm{Tb}$; se Tmáx > TB, então Tmáx = TB, (7).

Em que Tmed é a temperatura média diária do ar, calculada pela média aritmética entre a temperatura mínima (Tmín) e a temperatura máxima (Tmáx) diária do ar; e Tb, Tot e TB são as temperaturas cardinais de aparecimento de folhas (temperatura base inferior, temperatura ótima e temperatura base superior, respectivamente). Consideraram-se $\mathrm{Tb}=7,2^{\circ} \mathrm{C}$ (SANGOI ; SILVA, 1986), Tot $=27^{\circ} \mathrm{C}\left(\right.$ EMBRAPA, 2002) e TB $=35^{\circ} \mathrm{C}$ (STRECK et al. 2003b).

A soma térmica diária foi acumulada a partir da emergência e resultou na soma térmica acumulada (STa, ${ }^{\circ} \mathrm{C}$ dia), calculada por:

$$
S T a=\Sigma S T d
$$

Considerou-se um novo nó quando a folha associada a esse nó apresentava-se expandida, considerado o momento em que as bordas das folhas já se apresentavam planas, sem encurvamento. Assim, foi avaliado de dois em dois dias o número de folhas de cada cultivar, desde a emissão do primeiro par de folhas até quando estas não variavam mais.

Dessa forma, para cada método de cálculo da soma térmica, calculou-se o desvio padrão (DP) da variável plastocrono, para cultivar Embrapa 122 e Catissol. O DP foi utilizado para selecionar o método de cálculo da soma térmica para determinação do plastocrono, pois essa estatística descritiva é uma medida de dispersão da variável analisada. Após selecionar o melhor método de cálculo da soma térmica, as médias de número de nós foram submetidas à análise de regressão. As equações de estimativa de plastocrono foram obtidas por meio do aplicativo Office Excel.

\section{RESULTADO E DISCUSSÃO}

O valor de plastocrono foi maior com o Método 1 e 2, e menor com o Método 5 para ambas as cultivares (Embrapa - 122 e Catissol), com variação entre $125,46{ }^{\circ} \mathrm{C}$ e $1834,42{ }^{\circ} \mathrm{C}$ dia folha ${ }^{-1}$ para a cultivar Catissol e $134,91^{\circ} \mathrm{C}$ e $1777,50{ }^{\circ} \mathrm{C}$ dia folha ${ }^{-1}$ para a Embrapa - 122, conforme Tabela abaixo.

Os valores de STd obtidos pelos métodos 1 e 2, foram similares, pois a Tméd e a Tmín não foram inferiores à $\mathrm{Tb}$, visto que se a Tmed fosse inferior à $\mathrm{Tb}$ a STd obtida pelo Método 1 seria 0 (zero), e se a Tmin fosse inferior à Tb a STd obtida pelo Método 2 seria maior. Já os métodos 5 e 6 apresentaram os menores valores de plastocrono, isso pode ser explicado pelo fato da fórmula aplicada para obtenção desses valores serem diferente dos demais métodos estudados (Tabela 1). 
Tabela 1: Média \pm desvio-padrão do plastocrono $\left({ }^{\circ} \mathrm{C}\right.$ dia folha $\left.{ }^{-1}\right)$ de duas cultivares de girassol calculada através de seis métodos.

MÉTODO DE CÁLCULO DA SOMA TÉRMICA

\begin{tabular}{ccccccc}
\hline Cultivar & $\begin{array}{c}\text { Métodos 1 } \\
\text { (equação 2) }\end{array}$ & $\begin{array}{c}\text { Método 2 } \\
\text { (equação 3) }\end{array}$ & $\begin{array}{c}\text { Método 3 } \\
\text { (equação 4) }\end{array}$ & $\begin{array}{c}\text { Método 4 } \\
\text { (equação 5) }\end{array}$ & $\begin{array}{c}\text { Método 5 } \\
\text { (equação 6) }\end{array}$ & $\begin{array}{c}\text { Método 6 } \\
\text { (equação 7) }\end{array}$ \\
\hline $\begin{array}{c}\text { Embrapa 122 } \\
\text { Catissol }\end{array}$ & $1777,50 \pm 1,46$ & $1777,50 \pm 1,46$ & $1287 \pm 0,00$ & $1174,01 \pm 1,30$ & $134,91 \pm 1,96$ & $923,16 \pm 3,23$ \\
\hline Media & $1834,42 \pm 1,52$ & $1806,07 \pm 1,52$ & $1306,8 \pm 0,00$ & $1193,71 \pm 1,18$ & $125,46 \pm 1,76$ & $933,30 \pm 2,93$ \\
\hline
\end{tabular}

O desvio padrão (DP) do plastocrono com a soma térmica calculada pelos seis métodos (equações 2 a 7) variou de 0,00 a $2,93{ }^{\circ} \mathrm{C}$ dia folha ${ }^{1}$ para a cultivar Catissol e 0,00 a $3,23{ }^{\circ} \mathrm{C}$ dia folha ${ }^{-1}$ para a Embrapa - 122 (Tabela 1). Os métodos 6 e 3 apresentaram maior e menor desvio padrão, respectivamente, para as duas cultivares avaliadas, Catissol e Embrapa 122.

No cálculo da Soma térmica pelo Método 3, considera-se a resposta da emissão de folhas às duas temperaturas cardinais ( $\mathrm{Tb}$ e Tot), e a comparação das temperaturas cardinais é feita com a temperatura média (Tmed) do ar. Esse deve ser, portanto, o método a ser utilizado para calcular o plastocrono em girassol, para as cvs. estudadas, pois a emissão de folhas é resultado de processos que envolvem diferenciação dos primórdios foliares, divisão e crescimento celular. Esses processos são desencadeados por reações enzimáticas que, por sua natureza proteica, desnaturam em temperaturas elevadas, e a velocidade de catalisação das reações químicas é reduzida quando a temperatura é superior a uma temperatura ótima (STRECK, 2004).

Analisando o plastocrono nos seis métodos utilizados, Figuras 1 e 2 abaixo, a obtenção de temperatura média diária, para o cálculo da soma térmica acumulada, variou para os métodos 1 e 2 de 58,48 a $47,17^{\circ} \mathrm{C}$ dia nó entre as cultivares (Embrapa - 122 e Catissol), respectivamente, de 42,55 a 34,25 ${ }^{\circ} \mathrm{C}$ dia nó para o Método 3, de 38,46 a $31,15^{\circ} \mathrm{C}$ dia nó para o Método 4 , de 4,10 a $3,67{ }^{\circ} \mathrm{C}$ dia nó para o Método 5 e de 31,25 a $24,94{ }^{\circ} \mathrm{C}$ dia nó para o Método 6 em todo o ciclo da cultura, compreendido da emergência até a senescência da planta quando esta, fisiologicamente, cessa a sua taxa na emissão de nós na haste principal.

Também é possível observar uma relação linear entre NN e STa, com coeficientes de determinação $\left(\mathrm{R}^{2}\right)$ superiores a 0,85 . Esta linearidade entre NN e STa indica que a temperatura do ar é o fator ecológico principal que governa o aparecimento de nós na cultura do girassol. Um exemplo da relação entre número de nós acumulados na haste principal (NN) e a soma térmica acumulada (STa), para duas cultivares (Embrapa-122 e Catissol) no ano agrícola de 2014, são apresentados nas Figuras 1 e 2. 
Figura 1: Relação entre número de nós acumulados na haste principal da planta (NN, nós planta $\left.{ }^{-1}\right)$ e soma térmica acumulada (STa, ${ }^{\circ} \mathrm{C}$ dia) dos seis métodos, utilizada para estimativa do plastocrono na cultivar Catissol. Capitão Poço, 2014.
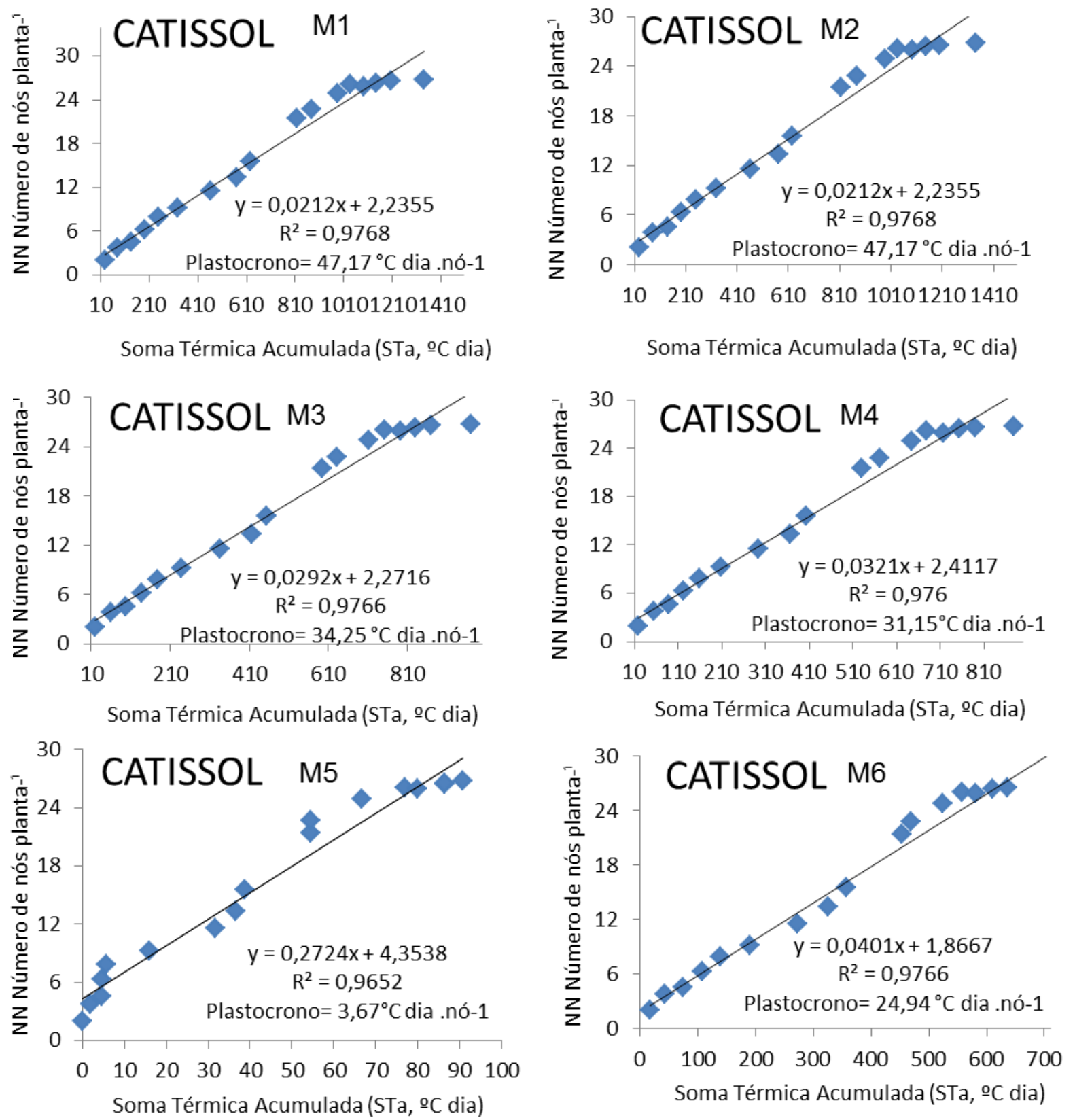
Figura 2: Relação entre número de nós acumulados na haste principal da planta (NN, nós planta $\left.{ }^{-1}\right)$ e soma térmica acumulada (STa, ${ }^{\circ} \mathrm{C}$ dia) dos seis métodos, utilizada para estimativa do plastocrono na cultivar Embrapa - 122. Capitão Poço, 2014.
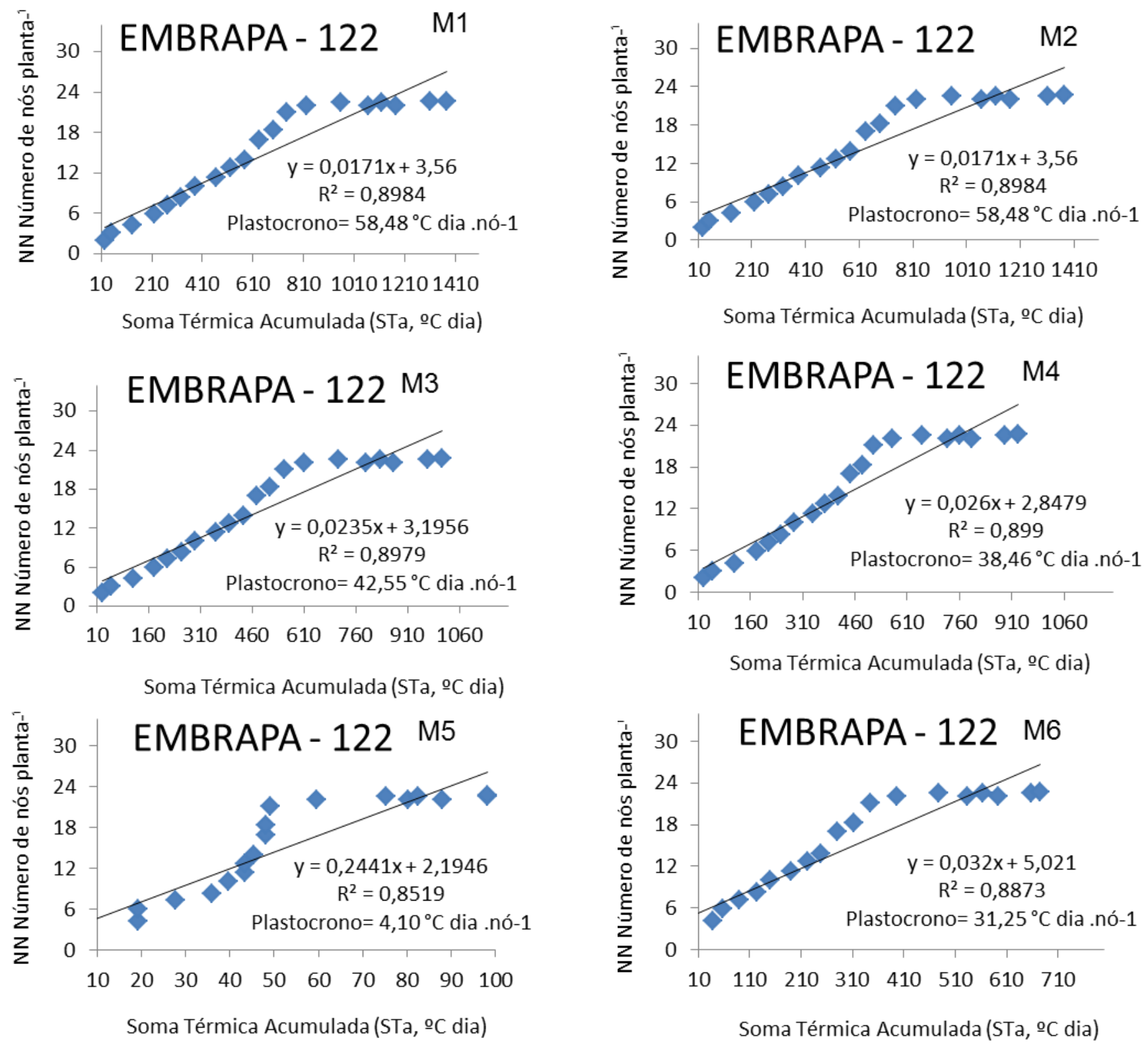

Os menores valores de plastocrono observados no Método 5 para ambas as cultivares, foram devido a condição do método aplicado.

Streck et al. (2005), estudando a estimativa do plastocrono em meloeiro (Cucumis melo L.) cultivado em estufa plástica em diferentes épocas do ano em Santa Maria, RS, obtiveram os maiores valores de plastocrono de $21,8^{\circ} \mathrm{C}$ dia nó ${ }^{-1}$ com semeadura em Fevereiro e Transplantil em Março de 2003, com Temperatura média do ar $\left({ }^{\circ} \mathrm{C}\right)$ de $19,8{ }^{\circ} \mathrm{C}$, e $21,3{ }^{\circ} \mathrm{C}$ dia nó ${ }^{-1}$ com semeadura em Agosto e transplantil em Outubro de 2004 e Temperatura média do ar $\left({ }^{\circ} \mathrm{C}\right)$ de $22{ }^{\circ} \mathrm{C}$. O plastocrono calculado entre as épocas de cultivo variou de 13,4 a $21,8^{\circ} \mathrm{C}$ dia nó ${ }^{-1}$. Pesquisa desenvolvida por Toebe et al. (2010) com a cultura do crambe concluíram que, para a obtenção de estimativas seguras de plastocrono em crambe, a melhor subdivisão do seu ciclo é da emergência até o início do florescimento e do início do florescimento até o início da frutificação onde o subperíodo apresenta variação de 28,3 a $47,8^{\circ} \mathrm{C}$ dia nó ${ }^{-1}$. 
Por ser um método de cálculo simples e que geralmente melhora a predição da data de ocorrência de estágios de desenvolvimento em plantas comparado com dias do calendário civil ou número de dias após a semeadura ou plantio (GILMORE ; ROGERS, 1958), a soma térmica é um método atrativo e muito utilizado para representar tempo biológico em plantas.

No entanto, segundo Streck et al. (2003a,b), apesar destas vantagens, o método está aberto a críticas devido ter a pressuposição de uma relação linear entre desenvolvimento e temperatura. Esta pressuposição é adequada apenas para uma faixa de temperatura entre a temperatura base e a temperatura ótima. Próximo às temperaturas cardinais, a resposta do desenvolvimento vegetal à temperatura é não linear.

De acordo com Streck et al. (2005), quando o ciclo da cultura ocorre na época recomendada para o seu cultivo, geralmente as temperaturas se enquadram na faixa de bem. No entanto, resposta linear de desenvolvimento à temperatura, e, neste caso, a soma térmica funciona ainda segundo os mesmos autores, quando o cultivo é realizado fora da época recomendada, a soma térmica nem sempre funciona adequadamente. Deste modo, o uso da soma térmica como medida de tempo no plastocrono na cultura do girassol, deve ser feito com precaução.

\section{CONCLUSÃO}

O melhor método para estimativa do plastocrono nas condições estudada é o Método 3, que leva em consideração a temperatura média, a temperatura base inferir e a temperatura ótima, pois foi o que apresentou menor desvio padrão em relação aos demais métodos.

\section{REFERENCIAS}

ARNOLD, C. Y. The determination and significance of the base temperature in a linear heat unit system. Proceedings of the American Society for Horticultural Science, v.74, p.430-445, 1959.

CONAB- Companhia Nacional de Abastecimento. Indicadores da Agropecuária. Brasília: Ministério da Agricultura, Pecuária e Abastecimento, 2010, 37 p. disponível em:

http://www.conab.gov.br/OlalaCMS/uploads/arquivos/ea8aad8f1c1cffcb94e9da7146566449 .Acesso em: 20 jan. 2016.

EMBRAPA - EMPRESA BRASILEIRA DE PESQUISA AGROPECUÁRIA. Resultado de pesquisa da EMBRAPA Soja - 2001: girassole trigo. Londrina: EMBRAPA Soja, 2002. 21p.

EMBRAPA- EMPRESA BRASILEIRA DE PESQUISA AGROPECÚARIA. Sistema brasileiro de classificação de solos. 3. ed. Rio de Janeiro, 2006. 306p.

FAGUNDES, J.D. et al. Temperatura base, plastocrono e número final de nós no malmequer-do-campo. Ciência Rural, v.38, p.2471-2477, 2008.

FARIAS, V. D DA. S.et al. Temperaturas basais e necessidade térmica para o ciclo de desenvolvimento do feijão-caupi. ENCICLOPÉDIA BIOSFERA, Centro Científico Conhecer - Goiânia, v.11 n.21; p. $1781,2015$.

FERNEDA, B. G.et al. Graus-dias na estimativa das taxas de crescimento de quatro cultivares de soja em diferentes épocas de plantio. Nativa, v. 4, n. 3, p. 121-127, 2016. 
GILMORE JUNIOR., E. C.; ROGERS, J. S. Heat units as a method of measuring maturity in corn. Agronomy Journal, v. 50, n. 10, p. 611-615, 1958.

LUCAS, D. D. P.et al. Temperatura base para emissão de nós e plastocrono de plantas de melancia. Revista Ciência Agronômica, v. 43, n. 2, p. 288-292, 2011.

MARTIN, F. B.; REIS, D DA. F.; PINHEIRO, M. V. M. Base temperature and phyllochron in two olive cultivars. Ciência Rural, v.42, n.11, nov, 2012.

MENDONÇA, H. F. C.et al. Estimativa do filocrono de morangueiro em sistemas consorciado e solteiro em ambientes protegidos. Rev. Bras. Frutic., Jaboticabal - SP, v. 34, n. 1, p. 015-023, Março 2012.

PEREIRA, L. C.; CAMPELO JÚNIOR, J. H.; FERRONATO, A. Comparação de Métodos para Estimativa do Plastocrono em Algodoeiro em Condições Tropicais. Pesquisa Agropecuária Tropical, v.40, n.2, p.213-220, 2010.

SANGOI, L.; SILVA, P.R.F. Comparação entre métodos de cálculo de unidades térmicas e os dias do calendário na previsão de subperíodos de desenvolvimento do girassol. Pesquisa Agropecuária Brasileira, Brasília, v.21, p.901-908, 1986.

SCHWART, G. Manejo sustentável de florestas secundárias: espécies potenciais no Nordeste do Pará, Brasil. Amazônia: Ciência; Desenvolvimento, Belém, v.3, n.5, p.125-147, 2007.

SCHWERZ, F.et al. Evaluation of the effect of doses and sources of nitrogen on morphological variables, radiation interception and yield of sunflower. Revista Ceres, v. 63, n. 3, p. 380-386, 2016. http://dx.doi.org/10.1590/0034-737X201663030015.

SILVA, A. G. et al. Infestação Da Mosca-Negra-Dos-Citros Em Pomares De Citros, Em Sistemas De Plantio Convencional E Agroflorestal. Rev. Bras. Frutic., Jaboticabal - SP, v. 33, n. 1, p. 053-060, Março 2011.

SILVA, E. E.et al. Manejo da adubação nitrogenada na cultura do girassol para avaliação dos parâmetros crescimento e produção. Revista do Instituto Federal de Educação, Ciência e Tecnologia da Bahia. Ano 14, n. 14, 2016.

STRECK, N.A. A temperature response function for modeling leaf growth and development of the African violet (Saintpaulia ionantha Wendl.). Ciência Rural, v.34, p.55- 62, 2004.

STRECK, N. A.et al. Estimativa do plastocrono em meloeiro (Cucumis melo L.) cultivado em estufa plástica em diferentes épocas do ano. Cienc. Rural. v.35 n.6 Santa Maria. nov./dec. 2005.

STRECK, N.A.et al. Improving predictions of developmental stages in winter wheat: a modified Wang and Engel model. Agricultural and Forest Meteorology, v.115, p.139- 150, 2003 a.

STRECK, N.A.et al. Incorporating a chronology response into the prediction of leaf appearance rate in winter wheat. Annals of Botany, v.92, p.181-190, 2003 b.

STRECK, N. A. et al. Estimativa do plastocrono em meloeiro (Cucumis melo L.) cultivado em estufa plástica em diferentes épocas do ano. Ciência Rural, v. 35, n. 02, p. 1275-1280, 2005.

STRECK, N.A.et al. Filocrono de genótipos de arroz irrigado em função da época de semeadura. Ciência Rural, v.37, p.323- 329, 2007a.

STRECK, N.A.et al. Simulating the development of field grown potato (Solanum tuberosum L.). Agricultural and Forest Meteorology, v.142, p.1- 11, $2007 \mathrm{~b}$.

TOEBE, M.et al. Estimating the plastochron in crambe. Ciência Rural, v. 40, n. 4, p. 793-799, 2010. 
TAZZO, I. F.et al. Heat requirement of two selections and four strawberry cultivars grown in the catarinense plateau. Revista Brasileira de Fruticultura, v. 37, n. 3, p. 550-558, 2015.

WILHELM, W.W.; McMASTER, G.S. Importance of the phyllochron in studying development and growth in grasses. Crop Science, v.35, p.1-3, 1995. 